\title{
Effectiveness of Silanization and Plasma Treatment in the Improvement of Selected Flax Fibers' Properties
}

\author{
Weronika Gieparda *(D), Szymon Rojewski (D) and Wanda Różańska \\ Institute of Natural Fibres \& Medicinal Plants-National Research Institute, Wojska Polskiego 71B, \\ 60-630 Poznań, Poland; szymon.rojewski@iwnirz.pl (S.R.); wanda.rozanska@iwnirz.pl (W.R.) \\ * Correspondence: weronika.gieparda@iwnirz.pl
}

Citation: Gieparda, W.; Rojewski, S.; Różańska, W. Effectiveness of Silanization and Plasma Treatment in the Improvement of Selected Flax Fibers' Properties. Materials 2021, 14 , 3564. https://doi.org/10.3390/ ma14133564

Academic Editor: Francisco Javier Espinach Orús

Received: 1 June 2021

Accepted: 23 June 2021

Published: 25 June 2021

Publisher's Note: MDPI stays neutral with regard to jurisdictional claims in published maps and institutional affiliations.

Copyright: (c) 2021 by the authors. Licensee MDPI, Basel, Switzerland. This article is an open access article distributed under the terms and conditions of the Creative Commons Attribution (CC BY) license (https:// creativecommons.org/licenses/by/ $4.0 /)$.

\begin{abstract}
The study investigated the effectiveness of the combination of chemical and physical methods of natural fibers' modification. The long flax fibers were subjected to various types of modification. These were silanization, plasma modification and a combination of these methods. For the silanization process, two types of silanes were used: amino- and vinylsilane. The application of structurally different compounds allowed us to acquire knowledge about the effect of the modifier structure on its properties. Various properties of flax fibers were investigated, comparing the results before and after different modification processes. The flammability of prepared samples were tested by pyrolysis combustion flow calorimeter (PCFC). In the effect of the natural fibers' modifications, flammability was reduced even by $30 \%$. The thermal stability of modified fibers increased. The FTIR tests of the gases released during thermal degradation of the tested fibers allowed us to determine the important compounds and prove a lower degree of flax-fiber decomposition after modification. Flax fibers were also tested to evaluate their physical properties (linear mass, average diameter, aspect ratio and hygroscopicity). Changes in surface morphology were observed by scanning electron microscope (SEM). The properties of natural fibers improved significantly, thus contributing to an increase in their suitability for the use in composites.
\end{abstract}

Keywords: natural fibers; modification; plasma treatment; silanization; flammability; thermal stability; scanning electron microscopy; fibers evaluation

\section{Introduction}

Natural fibers are, among others, one of the fillers in the polymers, in order to improve the properties of the finished products. Polymer materials are an integral part of our everyday life. It is important to note that the usage of synthetic materials that are not biodegradable has polluted the environment to an alarming level [1]. Better awareness and willingness to care for the environment makes people more often turn to natural materials. Products manufactured from pure polymers are frequently replaced by those made from composites filled with natural raw materials. Decades ago, only the textile and packaging industries used natural fibers. However, advances made in the field of natural fibers and their hybrids constitue a worthy alternative to materials used in numerous conventional industries, such as the construction, aerospace or automotive industries [2]. Implementing natural-fiber-based materials instead of synthetic composites in a vehicle can result in a significant (up to $40 \%$ ) reduction of weight. In this industry, many interior items were made exclusively of pure polymers, and this situation created a fire hazard. There can be many solutions to this problem, such as the addition of flame retardants or various types of synthetic, mineral or natural additives. Each approach has certain advantages, but the use of a natural filler in the form of lignocellulosic natural fibers seems to be the most appropriate one. Numerous polymer elements of vehicles can be replaced with bio-composites reinforced with natural fibers, e.g., interior insulation, seat bottom, door panels, dashboard, body panels, boot liner, etc. By their use, not only reduction of 
flammability of the prepared element, but also increased biodegradability and reduced mass, and thus reduced weight of the whole vehicle, can be obtained, leading to lower fuel consumption. Despite these advantages, composites with natural fibers have a few weaknesses, such as poor chemical and fire resistance, poor melting temperature, poor interfacial bonding between matrix and fibers, poor moisture absorption, etc. $[1,3]$. The disadvantages mentioned make it necessary to conduct surface treatment of the natural fibers before incorporating them into composites. In order to achieve good parameters, they should be modified also for further flammability reduction. For this purpose, either chemical or physical methods can be used.

Chemical structure of fibers and polymer matrix are different. Natural fibers consist of hemicellulose, lignin, pectin, water and waxy soluble substances $[4,5]$. In composites, to the hydrophobic polymer matrix, hydrophilic natural fibers are introduced. As a result, ineffective stress transmission across the interface of the composites is observed due to poor adhesion $[4,6]$. To deal with this problem, chemical methods of natural-fiber modification, such as mercerization, acetylation, benzoylation, steric acid treatment and silanization, can be used [6,7]. The silanization method offers a wide range of possibilities, due to the possibility of using compounds with various chemical structures adapted to the type of polymer matrix used in the composite [8]. This method involves reacting with hydroxyl groups on the surface of the fibers. However, its undoubted advantage is that the silanes not only react with the fibers, but also condense to form a thin protective coating that is able to give additional properties. Numerous studies have shown that the modification of natural fibers by silanization has a positive effect on improving the water resistance of the fibers, increasing the surface wettability of natural fibers by polymers and promoting interfacial adhesion, and additionally reduces flammability and improves their thermal stability $[9,10]$. As a result, the properties of natural-fiber-reinforced composites are improved, e.g., flammability or mechanical properties such as tensile strength, flexural modulus, percentage elongation and water absorption, etc. [7].

In addition to the chemical methods used for natural fibers modification, there are also physical methods that are clean, dry and free from expensive and environmentally unfriendly chemicals [11]. Initial system costs (i.e., cost of equipment) can be high, but operators are not exposed to unsafe processes and system operating costs are minimal. Additionally, the high utilization costs associated with hazardous processes are eliminated in this case. These methods are mainly based on energy transfer to the surface of fibers to activate cellulose functional groups-hydroxyl groups. The energy causes breaking of chemical bond between hydrogen and oxide, and forming free radicals. The examples of these methods include plasma, corona or UV radiation [12-14]. Physical modifications induced by plasma treatment of the fibers surface can improve the compatibility with the polymer matrices $[15,16]$. Plasma treatment provides an opportunity to remove contaminants and weakly bound layers, enhance wettability by incorporating polar groups on the surface and to form functional groups permitting covalent bonding $[17,18]$. The improved interfacial bonding in fiber composites results in increased mechanical strength [3].

The influence of various types of physical and chemical modification of natural fibers on their properties has been widely analyzed in the literature. Miedzianowska et al. analyzed in her work [19] properties of silanized lignocellulosic filler and its application in natural rubber biocomposites. The influence of the conducted modifications by three types of silanes on the morphology and structure of straw particles was investigated. The increase in hydrophobicity and thermal stability of natural fibers was confirmed in their research. After the modification, the straw structure was less smooth and more dispersed. Kumarjyoti et al. have been studied the suitability of various chemical treatments to improve the performance of jute fibers filled natural rubber composites [20]. The surface of jute fibers was modified by three different surface treatments, alkali treatment, combined alkali/stearic, acid treatment and combined alkali/silane treatment. Interestingly, alkali/silane treatment was found to be most efficient surface treatment method to develop strong interfacial adhesion between natural rubber matrix and jute fibers. Referring in turn 
to the physical methods of modification of natural fibers Hamad et al. have investigated and quantified the effect of plasma-surface modification on ramie plant fibers [21]. It can be concluded from that paper that such treatment can be an effective method in modifying the fiber surface. The modification carried out in these studies led to a surface roughness which increases the surface area and leads to better wettability and interaction of the fiber with the matrix. It can be assumed that the application of plasma surface modification will bring enormous benefits in the production of fiber-polymer composites.

In this paper, the combination of chemical and physical methods used for the modification of natural fibers was presented. As a pretreatment, in order to improve the properties of natural fibers, a silanization process was performed. For even better results it was decided to use plasma modification after fibers silanization. The plasma process was applied at the end of technological chain of fibers modifications to provide them with more hydrophobic properties, improve silane condensation and give a better adhesion with the polymer matrix.

\section{Materials and Methods}

\subsection{Materials}

Natural fibers: Osmotically degummed flax fibers prepared by INF\&MP-NRI (Flax fibers); reagents for silanization: Acetic acid $80 \%$ pure p.a. and ethyl alcohol $96 \%$ pure p.a. supplied by Avantor Performance Materials Poland S.A., Gliwice, Poland, 3-(diethylene triamine) propyltrimethoxysilane (silane VII) and vinyl trimethoxysilane (silane VIII) provided by Unisil Sp. Z o.o., Tarnów, Poland.

\subsection{Fibers}

The degumming process was carried out with an experimental device operating in the periodic mode. In this method, the degumming process was based on usage of physical laws, especially of osmosis phenomenon, which is observed inside fibrous plant stems in contact with water. This method ensured obtaining the odor-free fibers without damage, characterized by light color and higher aspect ratio in comparison with the fibers extracted with the use of other methods, e.g., dew retting.

The laboratory tests on the degumming process were run at the $14 \mathrm{~kg}$ batches of flax straw. The process was carried out in the following conditions: water temperature of $30^{\circ} \mathrm{C}$, process time of $72 \mathrm{~h}$ and water flow rate of $30 \mathrm{dm}^{3} / \mathrm{min}$. During the processs, a C-type UV lamp was used for inhibiting the growth of retting microorganisms, which is a typical occurrence in the warm-water retting method. After osmotic degumming, the process of hydrodynamic rinsing of straw with cold water was applied, and then the excess water was wrung. Next, the straw was dried in at approximately $60^{\circ} \mathrm{C}$, for $48 \mathrm{~h}$.

\subsection{Modification}

\subsubsection{Silanization}

Two silanes with different structure and properties were used for the study-more polar nitrogen-containing aminosilane and less polar-vinylsilane. The work started with the parameter adjustment for fibers modification method. Due to the susceptibility to the rapid hydrolysis of the silanes, and then polymerization of the compound in aqueous solution, a silanization process was carried out in a mixture of water with ethanol in acidic medium (acetic acid). Parameters of the modification process, such as $\mathrm{pH}$, solution's concentration and modification time, were adjusted: $5 \%(w / w)$ silane (VII or VIII) solution in $\mathrm{C}_{2} \mathrm{H}_{5} \mathrm{OH} / \mathrm{H}_{2} \mathrm{O}(6 / 4)(v / v)$ with $\mathrm{pH}=4.5$. Modification was conducted for $1 \mathrm{~h}$, at the room temperature. After that, the fibers were drained and placed in a chamber set at $80^{\circ} \mathrm{C}$. Dry fibers were cured for $10 \mathrm{~min}$ at $105^{\circ} \mathrm{C}$. The parameters of the modification process were optimized in order to minimize fibers' damage, and for obtaining the highest reactivity and achieving the best yield of the silanization process. 


\subsubsection{Plasma Treatment}

Plasma treatment was conducted in a two-stage process. Plasma gas argon was used with flow: 143.3 SCCM for preliminary cleaning of the flax, at pressure inside the plasma chamber: $50 \mathrm{mTr}$, with discharge power $100 \mathrm{~W}$ for $1 \mathrm{~min}$. The main plasma treatment was conducted as the second stage of the process in the same pressure, with use of argon (the flow at 143.3 SCCM) and hexamethyldisiloxane (HMDSO) (the flow at 20 SCCM) for 10 min with discharge power $90 \mathrm{~W}$.

\subsection{Test Methods}

\subsubsection{Thermal Stability Tests}

Thermogravimetric study (TGA) was performed with a TA Instruments Analyser Q50, TA INSTRUMENTS, New Castle, DE, USA. A tested sample (about $20 \mathrm{mg}$ ) was subjected to heating within the temperature range from 30 to $650{ }^{\circ} \mathrm{C}$ and heating rate of $15^{\circ} \mathrm{C} / \mathrm{min}$ in nitrogen atmosphere at constant gas flow rate of $90 \mathrm{~mL} / \mathrm{min}$.

\subsubsection{Fourier Transform Infrared Spectrometry (FTIR) Analysis}

During TGA study the released gases were identified. The tests were performed with a TA Instruments iZ10 model, Thermo Fisher Scientific, Madison, WI, USA. The spectrum of the released gases contained 8 scans per second at a resolution of $4 \mathrm{~cm}^{-1}$ within the range from 600 to $4000 \mathrm{~cm}^{-1}$.

\subsubsection{Flammability Tests}

Flammability tests were carried out by pyrolysis combustion flow calorimeter (PCFC) from FTT. Tests were performed according to the standard of ASTM D7309-2007. The heating rate was $1^{\circ} \mathrm{C} / \mathrm{s}$. Pyrolysis temperature range was $75-750{ }^{\circ} \mathrm{C}$, and the combustion temperature was $900{ }^{\circ} \mathrm{C}$. The flow was a mixture of $\mathrm{O}_{2} / \mathrm{N}_{2} 20 / 80 \mathrm{~cm}^{3} / \mathrm{min}$ and the sample weight was $3-4 \mathrm{mg}$. The maximum heat release temperature $\left(\mathrm{T}_{\max }\right)$ and maximum heat release rate $\left(H R R_{\max }\right)$ were determined.

\subsubsection{Evaluation of Fibers}

A method of retting of natural fibers for their use in composites was presented in the paper published in Textile Research Journal in 2017 [22].

Flax fibers after modification were tested and compared with unmodified fibers to evaluate their properties: linear mass (tex), average diameter of divided "bundle" of fibers, aspect ratio and hygroscopity (65\%).

According to the Polish Standard PN-EN ISO 1973:2011 the linear mass (tex) of natural fibers was determined. Carried out under ambient conditions measurement of mass of separate bundles, made of 100 fibers cut to the length of $10 \mathrm{~mm}$ from flax fibers middle sections, made it possible to determine the average linear mass (tex) of fibers.

The average diameter of the fibers was determined on the basis of the surface area of a technical fibers cross-section. The aspect ratio (s) was determined as the ratio between the length (l) and the diameter (d) of the divided "bundle" of fibers, according to Equation (1):

$$
\mathrm{s}=1 / \mathrm{d},
$$

The cross-section and longitudinal views were photographed using microscopic test conducted with Hitachi S-3400N scanning electron microscope (SEM), Hitachi High Technologies America, Inc., Minato, Japan. The fibers were sprayed with conductive agent (gold) and the test was performed under high vacuum with 500 magnification, voltage $20 \mathrm{kV}$ and working distance $20 \mathrm{~mm}$.

A common problem is the ability of a textile product to absorb water vapor from the air. For the purposes of the research, the hygroscopicity of $65 \%$ was determined in accordance with the standard for evaluation of fibers and textiles. This parameter was expressed as the quotient of the difference between the mass of the sample stored in a 
desiccator at $100 \%$ air humidity and the dry mass of the sample by the dry mass of the sample, expressed as a percentage.

\section{Results}

In order to evaluate the effectiveness of the combination of various methods of fibers modification (silanization and plasma), the modification of the fibers was carried out in various variants. Both the silanization and the plasma modification separately, as well as the combined modifications with those methods were carried out.

\subsection{Thermal Stability}

The analysis of TGA/DTG curves for untreated flax fibers as well as or flax fibers after two-step modification are shown in the Figure 1. A specific values for the TGA analysis are additionally shown in the Table 1.

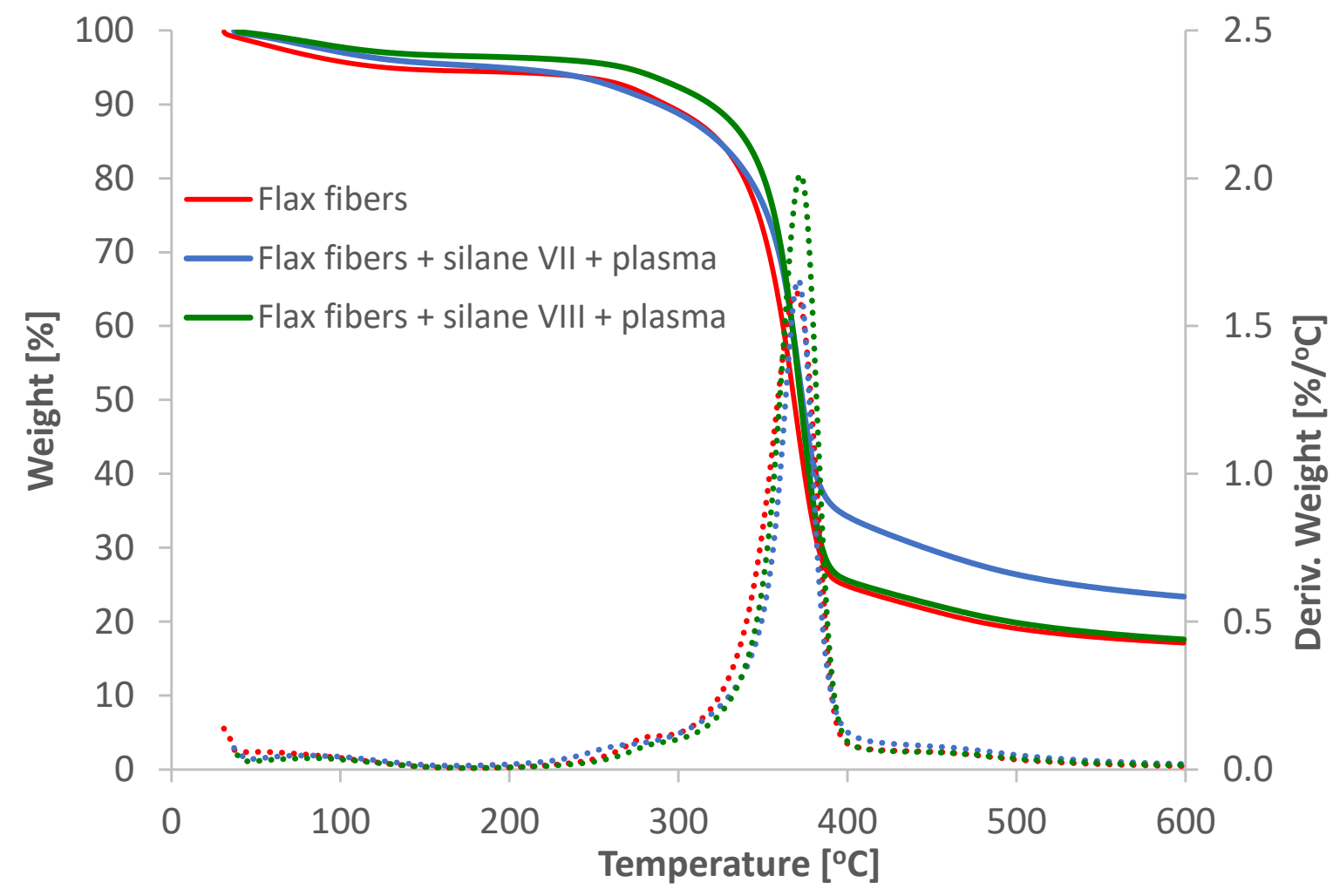

Figure 1. TGA results for unmodified and modified fibers.

Table 1. Values of TGA for long flax before and after modification.

\begin{tabular}{ccccccc}
\hline Type of Modification & $\begin{array}{c}\mathbf{T}_{\text {onset }} \\
\left({ }^{\circ} \mathbf{C}\right)\end{array}$ & $\begin{array}{c}\text { Weight } \\
\text { Change }(\mathbf{\%})\end{array}$ & $\begin{array}{c}\text { DTG Peak } \\
\left({ }^{\circ} \mathbf{C}\right)\end{array}$ & $\begin{array}{c}\text { Residue at Temperature } \\
\mathbf{6 0 0}{ }^{\circ} \mathbf{C}(\mathbf{\%})\end{array}$ & $\begin{array}{c}\mathbf{T}_{\mathbf{1 0}} \\
\left({ }^{\circ} \mathbf{C}\right)\end{array}$ & $\begin{array}{c}\mathbf{T}_{\mathbf{6 0}} \\
\left({ }^{\circ} \mathbf{C}\right)\end{array}$ \\
\hline Flax fibers & 348.40 & 65.08 & 369.49 & 17.12 & 292.09 & 374.55 \\
\hline Flax fibers + silane VII + plasma & 354.05 & 57.69 & 370.92 & 23.38 & 288.73 & 381.31 \\
\hline Flax fibers + silane VIII + plasma & 355.37 & 66.40 & 372.14 & 17.58 & 318.69 & 377.34 \\
\hline
\end{tabular}

The decomposition process can be divided into four stages [23]. First stage, which occurred at the temperature about $100^{\circ} \mathrm{C}$, was water evaporation and was characterized by $3.0-4.6 \%$ mass loss. Second stage, in which decomposition was taking place, occurred at the temperature of about $185-300^{\circ} \mathrm{C}$ and was characterized by $5.1-12.0 \%$ mass loss. Flax fibers that decomposed under these conditions produced mostly carbon dioxide and water. At the third stage the cellulose degradation occurred. It was the main stage of decomposition, 
mass loss was the highest and reached about $61.3-65.0 \%$ at temperature of about $370{ }^{\circ} \mathrm{C}$. Degradation of flax fibers led to production of carbon dioxide, formaldehyde, acetic and formic acids and water. In case of fibers modified by silane VII and plasma, ranging from about $380^{\circ} \mathrm{C}$, decrease of weight loss was observed. This may be due to interactions between conjugated cyclic structures formed from cellulose and the amine groups contained in used silane. "Crosslinking" that occurs between the above mentioned structures may affect the formation of graphite-like structures, which additionally improves thermal stability and increases coal yield [24]. Fourth stage-the longest stage of decomposition, occurred at temperature range from 250 to $600{ }^{\circ} \mathrm{C}$. This stage of decomposition was attributed to slow degradation of lignin and was characterized by $4.6-7.4 \%$ mass loss.

It is clear that used treatment of flax fibers improved their thermal stability, as shown by the shifted curves, to higher temperatures compared to untreated fibers. It is visible especially for fibers modified by plasma treatment and vinylsilane (silane VIII). The specific temperatures $\left(T_{\text {onset }}, T_{10}, T_{60}\right)$ were much higher than those for unmodified fibers as well as DTG peak was slightly shifted to higher temperatures. Numerous studies reported that unmodified fibers had lower decomposition temperature compared to modified fibers [25-28].

\subsection{Fourier Transform Infrared Spectrometry (FTIR) Analysis}

Compounds such as: carbon monoxide, carbon dioxide, water, acetic acid, formic acid and formaldehyde were determined on the basis of the FTIR analysis of the gases that were released during thermal degradation (TGA) of the fibers. The compounds list was shown in Table 2.

Table 2. The list of detected and identified compounds and their functional groups released during thermal decomposition of flax fibers.

\begin{tabular}{cccc}
\hline Compound Identified & Molecular Formula & Functional Group & Wave Number $\mathbf{~ m}^{-\mathbf{1}}$ \\
\hline Water & $\mathrm{H}_{2} \mathrm{O}$ & $\mathrm{OH}$ & 3737 \\
\hline Carbon dioxide & $\mathrm{CO}_{2}$ & $\mathrm{CO}_{2}$ & $2355 ; 2311 ; 671$ \\
\hline Carbon monoxide & $\mathrm{CO}$ & $\mathrm{CO}$ & 2182 \\
\hline \multirow{3}{*}{ Acetic Acid } & & $\mathrm{OH}$ & 3590 \\
& \multirow{2}{*}{$\mathrm{CH}_{3} \mathrm{COOH}$} & $\mathrm{C}=\mathrm{O}$ & $1795 ; 1770$ \\
& & $\mathrm{C}-\mathrm{O}$ & 1177 \\
& & $-\mathrm{CH}$ & 2976 \\
\multirow{2}{*}{ Formic Acid } & $\mathrm{OH}$ & 3590 \\
& \multirow{2}{*}{$\mathrm{CHOOH}$} & $\mathrm{C}=\mathrm{O}$ & $1795 ; 1770$ \\
& & $\mathrm{C}-\mathrm{O}$ & $1121 ; 1067$ \\
\multirow{2}{*}{ Formaldehyde } & $-\mathrm{CH}$ & 2910 \\
\hline
\end{tabular}

FTIR spectra for III ${ }^{\text {rd }}$ step (A) and IInd step (B) of thermal decomposition are shown in the Figure 2. Both in the case of the decomposition of the third and second thermal degradation stages, a clear reduction in the peaks responsible for the presence of carbon dioxide, carbon monoxide, acetic acid, formic acid and formaldehyde was observed: $\mathrm{CO}_{2}$ at $2355 \mathrm{~cm}^{-1}, \mathrm{C}=\mathrm{O}$ at 1770 and $1795 \mathrm{~cm}^{-1}, \mathrm{C}-\mathrm{HO}$ at $2780 \mathrm{~cm}^{-1}$, and $\mathrm{C}-\mathrm{O}$ at 1121 and $1177 \mathrm{~cm}^{-1}$. This proved a lower degree of flax fibers decomposition and confirmed the assumption that a part of lignin and hemicellulose was removed during the chemical modification process [29].

\subsection{Flammability}

Combustion parameters of unmodified and modified fibers measured by pyrolysis combustion flow calorimeter (PCFC) are presented in the Figures 3 and 4.

Modification performed only by the silanization method turned out to be effective only in the case of aminosilane (silane VII), which decreased $\mathrm{HRR}_{\max }$ by $30 \%$. Unfortunately, 
for vinylsilane (silane VIII), slight increase (6\%) of this parameter was observed. Fibers modification with plasma alone led to a $13 \%$ decrease in $H_{R R}$ max.
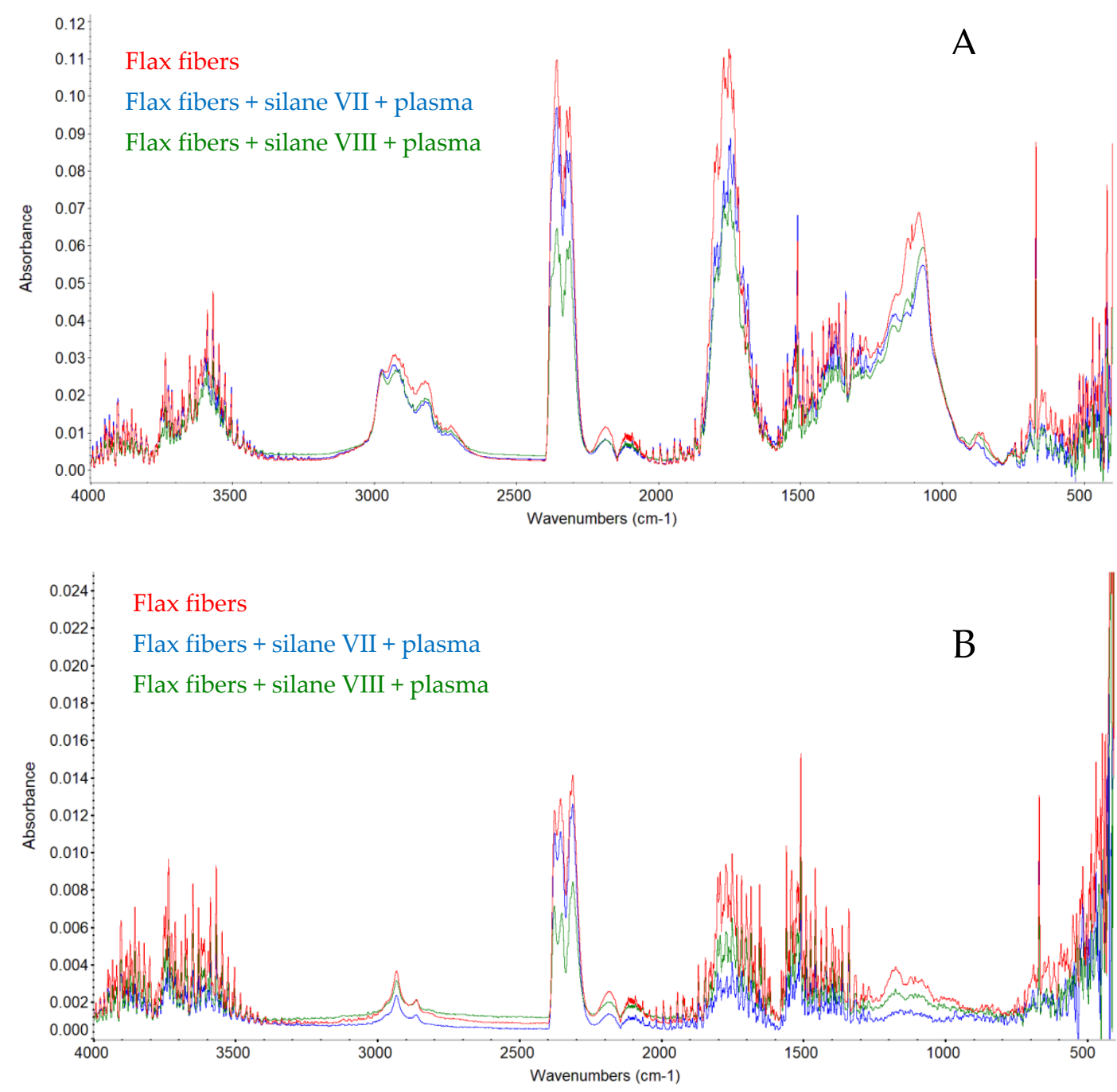

Figure 2. FTIR spectra for III ${ }^{\text {rd }}$ step (A) and II ${ }^{\text {nd }}$ step (B) of thermal decomposition unmodified and modified fibers.

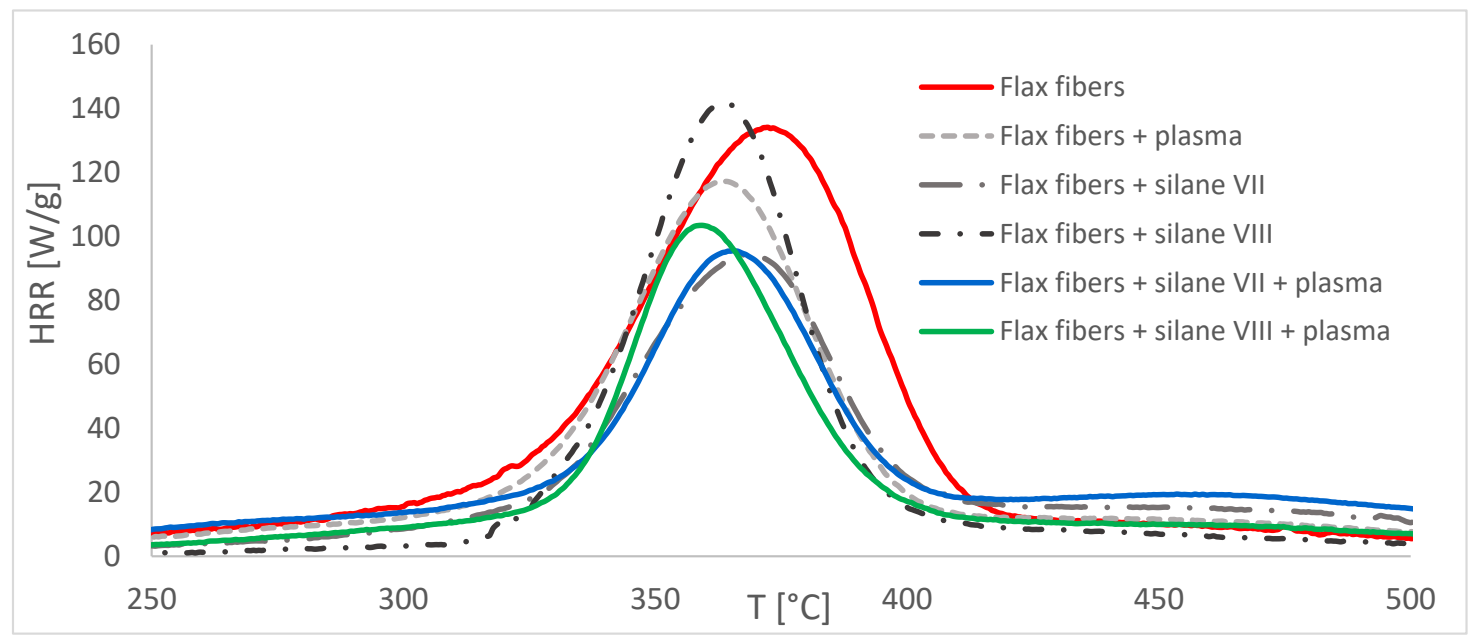

Figure 3. PCFC results for unmodified and modified fibers. 


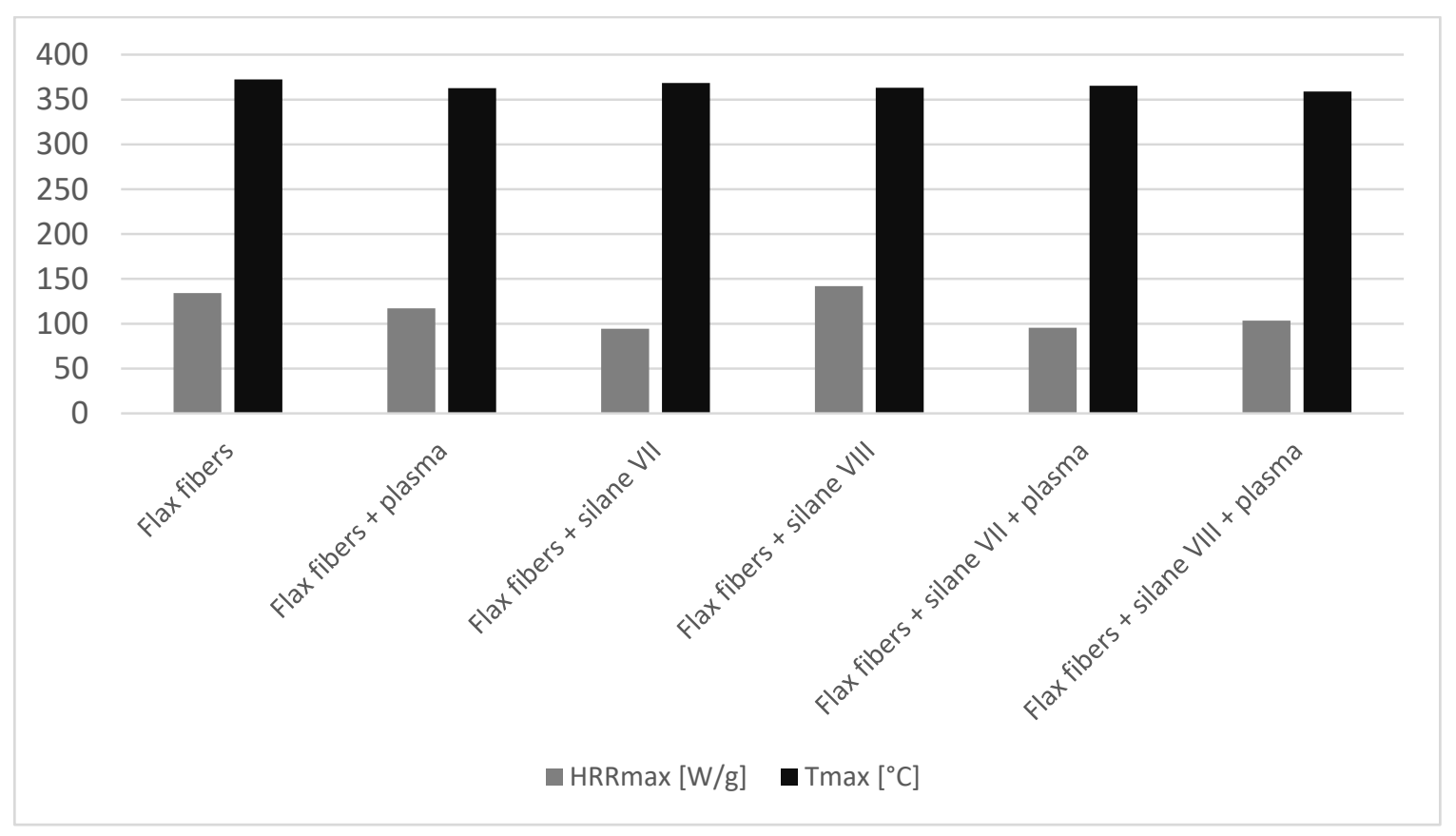

Figure 4. Comparison of $\mathrm{HRR}_{\max }$ and $\mathrm{T}_{\max }$ for unmodified and modified fibers.

The combination of both methods, in the case of the sample after modification with silane VII and plasma treatment, showed no further flammability reduction. $\mathrm{HRR}_{\max }$ in this case was comparable with the results of the sample modified with silane VII only (approximately 30\%). Interestingly, it should be emphasized, that for the sample chemically modified with silane VIII and then physically modified with plasma, there was a reduction of $\mathrm{HRR}_{\max }$ by $23 \%$. That was a better result than the summary results of both modifications applied separately. Therefore, it is clear that there was a synergistic effect in the combination of the physical and chemical methods of fibers modification. Initial silane coating of the fibers further increased the susceptibility of the fibers to plasma treatment.

For all modifications mentioned in this paper a visible decrease in $T_{\max }$ could be observed. This result occured due to the fact that each of the modifications affected the fibers in its own way, changing the structure of its surface by breaking the chemical bonds between hydrogen and oxide, some of the glycosidic bonds, creating free radicals and removing impurities $[13,17]$. The lowest reduction of $\mathrm{T}_{\max }$ was observed for fibers modified by silane VII, so the same sample, for which the best result in $\mathrm{HRR}_{\max }$ was obtained, and it was less than $4{ }^{\circ} \mathrm{C}$. Modification by the same silane VII in combination with plasma resulted in further reduction of $\mathrm{T}_{\max }$. Interestingly, the biggest reduction of $\mathrm{T}_{\max }$ was observed for natural fibers modified by silane VIII in combination with plasma. This type of modification resulted in $13^{\circ}$ reduction of $\mathrm{T}_{\max , "}$ that was $4{ }^{\circ} \mathrm{C}$ more than in case of modification by silane VIII used separately. For sample modified with the use of plasma only, the reduction was almost $10^{\circ} \mathrm{C}$. According to literature, it was also reported that $\mathrm{T}_{\max }$ can be declined in the modified fibers [28]. Thus, it can be assumed that combining more of them (modifications) together causes a further reduction of this parameter. This may be due to the fact that with each modification fibers of greater purity were obtained.

\subsection{Evaluation of Fibers}

The parameters of untreated fibers were compared with parameters of fibers modified in different process conditions and after each step of modification. Developed chemical and physical surface modification of flax fibers resulted in the changes in main parameters, such linear mass, diameter and aspect ratio, as well as the ability for moisture absorption (Table 3). 
Table 3. Evaluation of flax fibers, before and after chemical/physical modification.

\begin{tabular}{|c|c|c|c|c|c|c|c|c|}
\hline Type of Modification & $\begin{array}{l}\text { Linear } \\
\text { Mass } \\
\text { (tex) }\end{array}$ & $\begin{array}{c}\text { SD of Linear } \\
\text { Mass } \\
\text { (tex) }\end{array}$ & $\begin{array}{c}\text { Averadge } \\
\text { Diameter }^{1} \\
(\mu \mathrm{m})\end{array}$ & $\begin{array}{c}\text { SD of } \\
\text { Diameter } \\
(\mu \mathrm{m})\end{array}$ & $\begin{array}{c}\text { Aspect } \\
\text { Ratio }\end{array}$ & $\begin{array}{l}\text { SD of Aspect } \\
\text { Ratio }\end{array}$ & $\begin{array}{l}\text { Hygroscopicity } \\
65(\%)\end{array}$ & $\begin{array}{c}\text { SD of Hygro- } \\
\text { scopicity } 65 \\
(\%)\end{array}$ \\
\hline Flax fibers & 0.8 & 0.04 & 67.16 & 38.96 & 59.56 & 48.06 & 7.94 & 0.32 \\
\hline $\begin{array}{l}\text { Flax fibers + } \\
\text { silane VII }\end{array}$ & 1.0 & 0.08 & 50.15 & 27.33 & 103.50 & 50.30 & 8.39 & 0.14 \\
\hline $\begin{array}{l}\text { Flax fibers + } \\
\text { silane VIII }\end{array}$ & 0.6 & 0.00 & 32.68 & 16.26 & 146.17 & 53.11 & 7.20 & 0.53 \\
\hline $\begin{array}{l}\text { Flax fibers }+ \\
\text { Plasma }\end{array}$ & 0.6 & 0.07 & 24.85 & 8.93 & 178.34 & 53.91 & 5.39 & 0.17 \\
\hline $\begin{array}{c}\text { Flax fibers + } \\
\text { silane VII + Plasma }\end{array}$ & 0.6 & 0.07 & 30.50 & 15.98 & 158.68 & 60.64 & 4.08 & 0.21 \\
\hline $\begin{array}{c}\text { Flax fibers + } \\
\text { silane VIII + Plasma }\end{array}$ & 0.7 & 0.00 & 33.90 & 17.81 & 143.93 & 55.32 & 3.18 & 0.09 \\
\hline
\end{tabular}

${ }^{1}$ Average diameter of divided "bundle" of fibers.

Chemical and physical treatment of the fibers caused an increase in their surface area, as well as the structure became rougher. This is helpful, among other aspects, for better interfacial bonding [30]. It was clearly shown that untreated fibers had larger diameters than treated fibers. The chemical modification applied allowed it to attack the fibers' surfaces and break the lignin and hemicellulose web, and then it separated the fibers from the bundles [29]. The diameter of flax fibers was significantly smaller after silanization and plasma treatment. Importantly, the decreasing diameter of the fibers was also followed by their improved homogeneity. The standard deviation decreased proportionally with decreasing diameter. The treatment with plasma without silanization proved to be most effective treatment in diameter reduction among all the treatments. These results were consistent with those of silanized natural fibers presented in other publications [31]. Another significant change was the increase in the aspect ratio of the fibers. The modification with the plasma itself also had the greatest influence on this parameter. In this case, the aspect ratio increased more than threefold when comparing the degummed fibers and the plasma treated fibers. The most important disadvantage of natural fibers is their hydrophilic nature, which causes a poor interface between the fibers and the matrix in polymer composites. In addition, physical impurities and the presence of hydroxyl groups on the fibers surface make them difficult to use as reinforcing materials [32]. In this study, the hygroscopicity of the fibers was determined both before and after the modification processes. A significant reduction in the hygroscopicity of the fibers was observed, especially for silane-modified fibers in combination with plasma treatment. In this case, the hygroscopicity decreased more than twice. The modification also affected the linear mass (tex) of the fibers, reducing it by $25 \%$ compared to the untreated fibers.

Surface morphology of flax fibers before and after silanization, plasma and both were investigated to determine effect of modification processes on the fibers surface morphology. Table 4 shows SEM images of unmodified and modified flax fibers.

The surface condition of fibers is very important with regard to interfacial bonding between the fibers and the polymer matrix for better mechanics properties [33]. From the longitudinal view of flax fibers, it can be observed on the images that there were many impurities on the surface of untreated fibers. After chemical modifications, the surface was cleaner and smoother due to the formation of thin protective layer on it that was constructed from condensed silane. It was observed that the impurities were reduced after the treatment. This is consistent with other silane-modified natural fibers studies [26]. The analysis of SEM images allows for the assumption that silane treatment was a very helpful method for removal of lignin and hemicelluloses from natural fibers. That can enhance interfacial bonding between fibers and polymer [34,35]. In turn, taking into account the cross-section of the fibers, an increase in the specific surface area in the case of modified fibers was visible, as well as significantly changed structure and irregular shape of the 
fibers in the case of plasma modification was visible. That can be the effect of its excitation by plasma.

Table 4. SEM of unmodified and modified flax fibers.

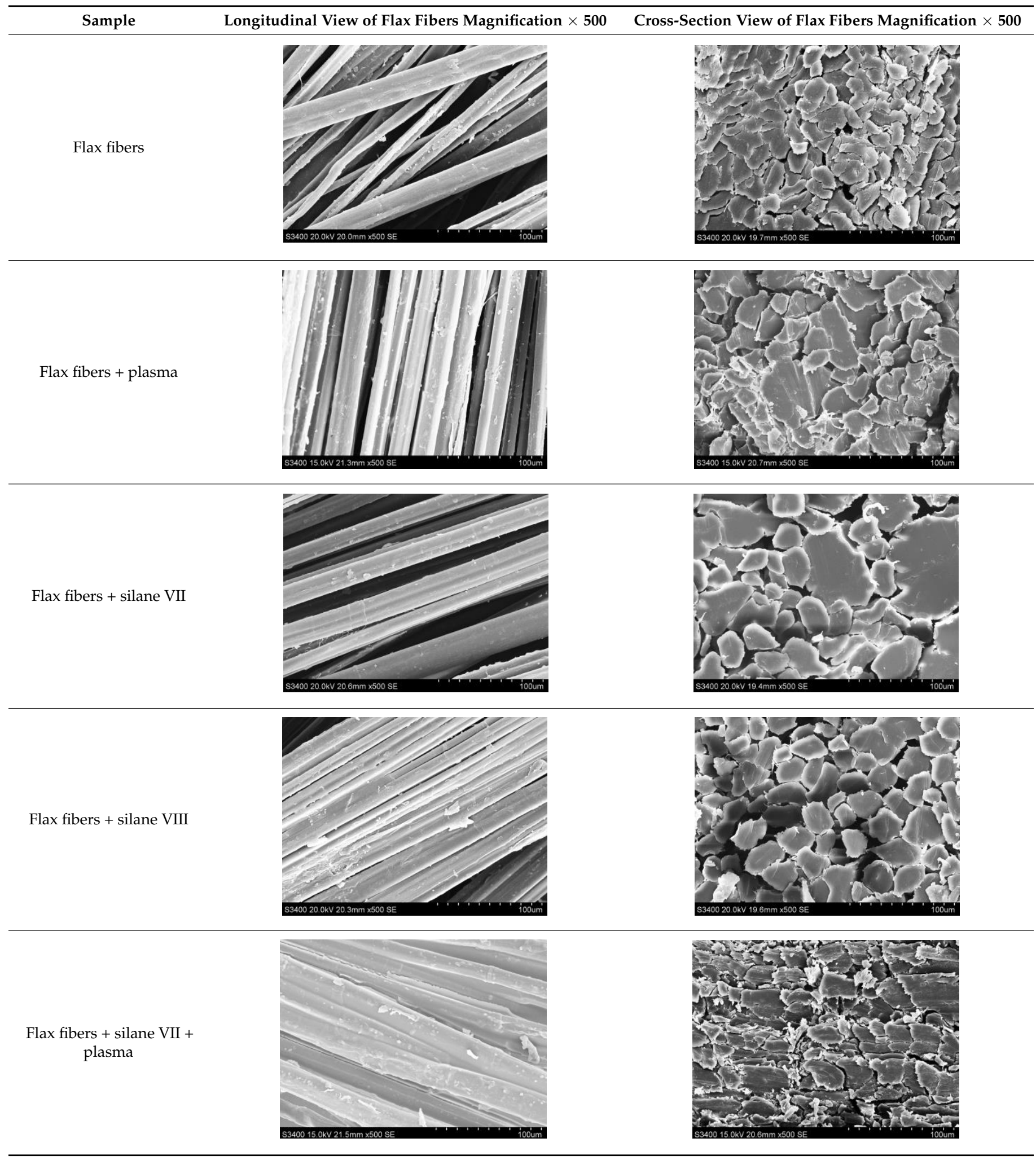


Table 4. Cont.

\begin{tabular}{cccc}
\hline Sample & Longitudinal View of Flax Fibers Magnification $\times 500$ & Cross-Section View of Flax Fibers Magnification $\times 500$ \\
\hline $\begin{array}{c}\text { Flax fibers + silane VIII + } \\
\text { plasma }\end{array}$
\end{tabular}

\section{Conclusions}

The aim of the study was to evaluate the influence of the combining chemical and physical modification of flax fibers on their properties. Obtained results of the research showed that the performed methodology allowed us to modify fibers successfully. Fibers modified by vinylsilane (silane VIII) and plasma had the best thermal stability among all of the modified fibers. The Fourier transform infrared spectroscopy of released gases during thermogravimetric analysis proved a lower degree of flax-fiber decomposition after modification. Based on the results from PCFC, it can be assumed that, in the case of fibers modification using silanization method with the compounds of suitable construction as pretreatment, followed by the plasma modification, it was possible to obtain a synergistic effect in the flammability reduction. It was shown that both modification using silane and plasma and their combination in a two-step process, with one exception (fibers modified by silane VIII), resulted in a reduction of flammability. SEM results showed no destruction of fibers surface, reduction of impurities on the fibers surface in the case of silane treatment and irregular surface after plasma treatment. The method of the flax fibers' modification used in this research also had a significant impact on the improvement of such properties of fibers as diameter, specific surface area or their hygroscopicity, which is important in the context of use in composites.

Author Contributions: Conceptualization, W.G. and S.R.; methodology, W.G., S.R. and W.R.; software, S.R.; validation, W.G., S.R. and W.R.; formal analysis, W.G. and S.R.; investigation, W.G., S.R. and W.R.; resources, W.G., S.R. and W.R.; data curation, W.G., S.R. and W.R.; writing-original draft preparation, W.G. and S.R.; writing—review and editing, W.G. and S.R.; visualization, W.G.; supervision, W.G.; project administration, S.R.; funding acquisition, W.G. All authors have read and agreed to the published version of the manuscript.

Funding: This research was funded by UE 7th Framework Programme, the Naturtruck ProjectDevelopment of a new Bio Composite, from renewable resources with improved thermal and fire resistance for manufacturing a truck internal part with high quality surface finishing.

Institutional Review Board Statement: Not applicable.

Informed Consent Statement: Not applicable.

Data Availability Statement: Not applicable.

Acknowledgments: The studies were carried out within the Naturtruck Project-Development of a new Bio Composite, from renewable resources with improved thermal and fire resistance for manufacturing a truck internal part with high quality surface finishing, financed by UE 7th Framework Programme.

Conflicts of Interest: The authors declare no conflict of interest. The funders had no role in the design of the study; in the collection, analyses or interpretation of data; in the writing of the manuscript; or in the decision to publish the results. 


\section{References}

1. Varghese, A.M.; Mittal, V. Surface modification of natural fibers. In Biodegradable and Biocompatible Polymer Composites, Processing, Properties and Applications; Woodhead Publishing Series in Composites Science and Engineering; Elsevier: Amsterdam, The Netherlands, 2018; pp. 115-155. [CrossRef]

2. Ferreira, D.P.; Cruz, J.; Fangueiro, R. Surface modification of natural fibers in polymer composites, In Green Composites for Automotive Applications; Woodhead Publishing Series in Composites Science and Engineering; Elsevier: Amsterdam, The Netherlands, 2019; pp. 3-41. [CrossRef]

3. Gupta, U.S.; Dhamarikar, M.; Dharkar, A.; Chaturvedi, S.; Kumrawat, A.; Giri, N.; Tiwari, S.; Namdeo, R. Plasma modification of natural fiber: A review. Mater. Today Proc. 2021, 43, 451-457. [CrossRef]

4. Doan, T.; Gao, S.; Mäder, E. Jute/polypropylene composites I. Effect of matrix modification. Compos. Sci. Technol. 2006, 66, 952-963. [CrossRef]

5. Bhattacharyya, D.; Subasinghe, A.; Kim, N.K. Natural fibers: Their composites and flammability characterizations. In Multifunctionality of Polymer Composites Challenges and New Solutions; Fridrich, K., Breuer, U., Eds.; William Andrew: Waltham, MA, USA, 2015; pp. 102-143.

6. Kabir, M.M.; Wang, H.; Lau, K.T.; Cardona, F. Chemical treatments on plant-based natural fibre reinforced polymer composites: An overview. Compos. Part B Eng. 2012, 43, 2883-2892. [CrossRef]

7. Godara, S.S. Effect of chemical modification of fiber surface on natural fiber composites: A review. Mater. Today Proc. 2019, 18, 3428-3434. [CrossRef]

8. Xie, Y.; Hill, C.; Xiao, Z.; Militz, H.; Mai, C. Silane coupling agents used for natural fiber/polymer composites: A review. Compos. Part A Appl. Sci. Manuf. 2010, 41, 806-819. [CrossRef]

9. Kabir, M.M.; Wang, H.; Lau, K.T.; Cardona, F. Effects of chemical treatments on hemp fiber structure. App. Surf. Sci. 2013, 276, 13-23. [CrossRef]

10. Dharmalingam, S.; Meenakshisundaram, O.; Kugarajah, V. Effect of degree of silanization of luffa on the properties of luffa-epoxy composites. Colloid Surf. A 2020, 603, 125273. [CrossRef]

11. Singh, M.; Vajpayee, M.; Ledwani, L. Eco-friendly surface modification of natural fibres to improve dye uptake using natural dyes and application of natural dyes in fabric finishing: A review. Mater. Today Proc. 2021, 43, 2868-2871. [CrossRef]

12. Ragoubi, M.; George, B.; Molina, S.; Bienaimé, D.; Merlin, A.; Hiver, J.; Dahoun, A. Effect of corona discharge treatment on mechanical and thermal properties of composites based on miscanthus fibres and polylactic acid or polypropylene matrix. Compos. Part A Appl. Sci. Manuf. 2012, 43, 675-685. [CrossRef]

13. Gassan, J.; Gutowski, V.S. Effects of corona discharge and UV treatment on the properties of jute-fibre epoxy composites. Compos. Sci. Technol. 2000, 60, 2857-2863. [CrossRef]

14. Popescu, M.C.; Totolin, M.; Tibirna, C.M.; Sdrobis, A.; Stevanovic, T.; Vasile, C. Grafting of softwood kraft pulps fibers with fatty acids under cold plasma conditions. Int. J. Biol. Macromol. 2011, 48, 326-335. [CrossRef]

15. Stalici, T.; Fiore, V.; Valenza, A. Effect of plasma treatment on the properties of Arundo Donax L. leaf fibres and its bio-based epoxy composites: A preliminary study. Compos. Part B Eng. 2016, 94, 167-175. [CrossRef]

16. Saria, P.S.; Thomas, S.; Spatenka, P.; Ghanam, Z.; Jenikova, Z. Effect of plasma modification of polyethylene on natural fibre composites prepared via rotational moulding. Compos. Part A Appl. Sci. Manuf. 2019, 177, 107344. [CrossRef]

17. Karahan, H.A.; Özdogan, E. Improvements of surface functionality of cotton fibers by atmospheric plasma treatment. Fibers Polym. 2008, 9, 21-26. [CrossRef]

18. Vander Wielen, L.C.; Östenson, M.; Gatenholm, P.; Ragauskas, A. Surface modification of cellulosic fibers using dielectric-barrier discharge. Carbohydr. Polym. 2006, 65, 179-184. [CrossRef]

19. Miedzianowska, J.; Masłowski, M.; Rybinski, P.; Strzelec, K. Properties of chemically modified (selected silanes) lignocellulosic filler and its application in natural rubber biocomposites. Materials 2020, 13, 4163. [CrossRef] [PubMed]

20. Kumarjyoti, R.; Subhas, C.D.; Lazaros, T.; Aphiwat, P.; Pranut, P. Effect of various surface treatments on the performance of jute fibers filled natural rubber (NR) composites. Polymers 2020, 12, 369. [CrossRef]

21. Hamad, S.F.; Stehling, N.; Hayes, S.A.; Foreman, J.P.; Rodenburg, C. Exploiting plasma exposed, natural surface nanostructures in ramie fibers for polymer composite applications. Materials 2019, 12, 1631. [CrossRef]

22. Konczewicz, W.; Zimniewska, M.; Valera, M.A. Selection of a retting method for extraction of bast fibres as response to challenges in composite reinforcement. Text. Res. J. 2017, 88, 2104-2119. [CrossRef]

23. Poletto, M.; Ornaghi Júnior, H.L.; Zattera, A.J. Thermal Decomposition of Natural Fibers: Kinetics and Degradation Mechanisms. In Reactions and Mechanisms in Thermal Analysis of Advanced Materials; Tiwari, A., Raj, B., Eds.; Scrivener Publishing LLC: Salem, MA, USA, 2015; pp. 515-546. [CrossRef]

24. Golova, L.K.; Makarov, I.S.; Bondarenko, G.N.; Mironova, M.V.; Berkovich, A.K.; Shandryuk, G.A.; Vinogradov, M.I.; Bermeshev, M.V.; Kulichikhin, V.G. Composite fibers based on cellulose and vinyltriethoxysilane as precursors of carbon material. Polym. Sci. Ser. B 2020, 62, 152-162. [CrossRef]

25. Zin, M.H.; Abdan, K.; Mazlan, N.; Zainudin, E.S.; Liew, K.E. The effects of alkali treatment on the mechanical and chemical properties of pineapple leaf fibres (PALF) and adhesion to epoxy resin. IOP Conf. Ser. Mater. Sci. Eng. 2018, 368. [CrossRef] 
26. Najeeba, M.I.; Sultanabc, M.T.H.; Yoshito, A.; Shahab, A.U.M.; Kubra, E.; Jawaidb, M.; Ariffine, A.H. Characterization of silane treated Malaysian Yankee Pineapple AC6 leaf fiber (PALF) towards industrial applications. J. Mater. Sci. Technol. 2020, 9, 3128-3139. [CrossRef]

27. Huda, M.S.; Drzal, L.T.; Mohanty, A.K.; Misra, M. Effect of chemical modifications of the pineapple leaf fiber surfaces on the interfacial and mechanical properties of laminated biocomposites. Compos. Interfaces 2008, 15, 169-191. [CrossRef]

28. Wladyka-Przybylak, M.; Wesolek, D.; Rojewski, S.; Gasiorowski, R.; Gieparda, W.; Bujnowicz, K.; Maciejewski, H.; Wojcik, R.; Nowicki, M. Synergistic Effect of Modified Natural Fibres with Halogen-Free Fire Retardants in Reducing Flammability of Composites. J. Biobased Mater. Bioenergy 2015, 9, 115-127. [CrossRef]

29. Kabir, M.M.; Wang, H.; Lau, K.; Cardona, F. Tensile properties of chemically treated hemp fibres as reinforcement for composites. Compos. Part B Eng. 2013, 53, 362-368. [CrossRef]

30. Goud, G.; Rao, R. Effect of fibre content and alkali treatment on mechanical properties of Roystonea regia-reinforced epoxy partially biodegradable composites. Bull. Mater. Sci. 2011, 34, 1575-1581. [CrossRef]

31. Asim, M.; Jawaid, M.; Abdan, K.; Ishak, M.R. Effect of Alkali and Silane Treatments on Mechanical and Fibre-matrix Bond Strength of Kenaf and Pineapple Leaf Fibres. J. Bionic Eng. 2016, 13, 426-435. [CrossRef]

32. Terpakova, E.; Kidalova, L.; Eštoková, A.; Čigášová, J.; Števulová, N. Chemical modification of hemp shives and their characterization. Procedia Eng. 2012, 42, 931-941. [CrossRef]

33. Meon, M.S.; Othman, M.F.; Husain, H.; Remeli, M.F.; Syawal, M.S.M. Improving tensile properties of kenaf fibers treated with sodium hydroxide. Procedia Eng. 2012, 41, 1587-1592. [CrossRef]

34. Asumani, O.M.L.; Reid, R.G.; Paskaramoorthy, R. The effects of alkali-silane treatment on the tensile and flexural properties of short fibre non-woven kenaf reinforced polypropylene composites. Compos. Part A Appl. Sci. Manuf. 2012, 43, 1431-1440. [CrossRef]

35. Puglia, D.; Monti, M.; Santulli, C.; Sarasini, F.; De Rosa, I.M.; Kenny, J.M. Effect of alkali and silane treatments on mechanical and thermal behavior of Phormium tenax fibers. Fibers Polym. 2013, 14, 423-427. [CrossRef] 